\title{
Anti-tissue transglutaminase antibodies from coeliac patients inhibit transglutaminase activity both in vitro and in situ
}

\author{
C Esposito, F Paparo, I Caputo, M Rossi, M Maglio, D Sblattero, T Not, R Porta, \\ S Auricchio, R Marzari, R Troncone
}

Gut 2002;51:177-181

See end of article for authors' affiliations

Correspondence to:

Professor C Esposito,

Department of Chemistry, University of Salerno, via' S Allende 84081, Baronissi (SA), Italy;

esposito@chem.unisa.it

Accepted for publication 6 November 2001

\begin{abstract}
Background and aims: Coeliac disease $(C D)$ is a multifactorial disorder which has an autoimmune component characterised by the occurrence of disease specific autoreactive antibodies against the enzyme tissue transglutaminase (tTG). The aim of this study was to investigate whether binding of antibodies to the enzyme influences ITG activity.

Methods: $+T G$ activity was assayed in the presence of immunoglobulin $A(\lg A)$ and immunoglobulin $G$ $(\mathrm{lgG})$ purified from the serum of coeliac patients, CUB 7402 (an anti-tTG mouse monoclonal antibody), and human anti-tTG monoclonal antibodies derived from both intestinal lymphocytes from three patients with $C D$ and from peripheral blood lymphocytes from healthy subjects. For our studies we used calcium treated and untreated recombinant human $\mathrm{TTG}$. Furthermore, the effects of antibodies were determined by immunohistochemical detection of tTG activity in sections of human umbilical cord.

Results: $\lg G$ and $\lg A$ from CD patients inhibited tTG activity in vitro in a dose dependent manner, with a different rate of inhibition among patients. The monoclonal antibody CUB 7402 and human monoclonal antibodies displayed a dose dependent inhibitory effect towards the catalytic activity of the enzyme, both in vitro and in situ. Preincubation of $\mathrm{tTG}$ with $\mathrm{CaCl}_{2}$ caused loss of the inhibitory effect due to CUB 7402 but not that caused by human monoclonal antibodies.

Conclusions: Purified CD lgA, lgG, as well as human anti-tTG monoclonal antibodies inhibited the enzymatic activity of human TTG both in vitro and in situ.
\end{abstract}

$\mathrm{T}$ ssue transglutaminase (tTG, EC 2.3.2.13) belongs to a family of $\mathrm{Ca}^{2+}$ dependent enzymes that catalyse posttranslational modification of peptides and proteins with the formation of isopeptide bonds between the $\gamma$-carboxamide group of protein bound glutaminyl residues and $\epsilon$ amino group of lysyl residues, present in the same or different polypeptide chain, or primary amines. ${ }^{1-3}$ tTG is widely distributed in vertebrate tissue and is a strongly regulated enzyme both transcriptionally and functionally. ${ }^{3-6}$ It appears to play a critical role in controlling cell and tissue homeostasis, regulating the cell cycle through its involvement in proliferation, terminal differentiation, and apoptosis. ${ }^{7}$ It is also present in extracellular compartments where it has a role in the stabilisation of the extracellular matrix and tissue repair by forming cross links between various substrate proteins. ${ }^{8}$ Finally, tTG is involved in the transduction of extracellular signals. In fact, tTG is a bifunctional enzyme with a transamidating catalytic activity on peptidyl glutamine residues as well as a guanosine triphosphate (GTP) hydrolysing activity, analogous to that of $G$ proteins, in adrenergic receptor transduction pathways. ${ }^{90}$ Other than its physiological roles, tTG mediated posttranslational modifications of proteins may represent a pathogenic mechanism in human diseases characterised by autoimmune phenomena, including coeliac disease (CD). ${ }^{11-13}$

$\mathrm{CD}$, or gluten sensitive enteropathy, is a multifactorial disease affecting approximately 1 in 200 Europeans. ${ }^{14}$ It is considered to be the result of a dysregulated $\mathrm{T}$ cell mucosal immune response to wheat gliadin and related prolamines of other toxic cereals (barley, rye, and possibly oats). ${ }^{14}$ It affects genetically susceptible individuals, with human leucocyte antigen genes playing a major role. ${ }^{15}$ Autoimmunity is an increasingly recognised feature of the disease; in fact, CD not only appears to be strongly associated with a series of autoimmune conditions, such as insulin dependent diabetes mellitus, thyroiditis, and Addison's disease, but is itself characterised by autoimmune phenomena. It has long been known that disease specific antibodies recognise proteins of the extracellular matrix ${ }^{16}$ and the target was recently identified by Dieterich et al as being tTG. ${ }^{17}$ This observation has had a large impact on diagnostic strategies for $\mathrm{CD}^{18} 19$ as well as providing new perspectives in the understanding of the disease mechanisms at both the local and systemic levels, reflecting the role of tTG in many crucial biological processes.

Recently, Marzari and colleagues ${ }^{20}$ isolated a series of antibodies to tTG by selecting phage display antibody libraries derived from either intestinal lymphocytes or peripheral blood lymphocytes from three patients with CD. They showed that whereas antigliadin responses could be selected from all libraries, the anti-tTG response was restricted to intestinal lymphocytes, involving the recognition of two main tTG epitopes. Here, we have investigated the effect of these antibodies, as well as that of immunoglobulin (Ig) purified from coeliac serum, on tTG catalytic activity. We report data showing that the interaction between anti-tTG antibodies and tTG inhibits the transamidating activity of the enzyme both in vitro and in situ. These results are discussed in relation to the still obscure role played by these autoantibodies in the pathogenesis of $\mathrm{CD}$.

Abbreviations: CD, coeliac disease; $\mathrm{tTG}$, tissue transglutaminase; Ig, immunoglobulin; GTP, guanosine triphosphate; MDCK, Madin-Darby canine kidney; EDTA, ethylenediamine-tetraacetic acid; PBS, phosphate buffered saline; BSA, bovine serum albumin; RT, room temperature; EGTA, ethylene glycol-bis( $\beta$-aminoethyl ether) $N, N, N^{\prime}, N^{\prime}$-tetraacetic acid DMC, N,N-dimethylated casein; bio-MDC, biotinylated monodansyl-cadaverine; TGF- $\beta$, transforming growth factor $\beta$. 


\section{MATERIALS AND METHODS}

\section{Cell culture and DNA transfection}

Madin-Darby canine kidney (MDCK) cells (European Cell Collection, 85011435) were grown in minimum essential medium (Life Technologies, Milan, Italy) supplemented with $10 \%$ fetal bovine serum, 10\% Earle's balanced salt solution, 50 $\mathrm{u} / \mathrm{ml}$ penicillin, $50 \mu \mathrm{g} / \mathrm{ml}$ streptomycin, and $1 \%$ non-essential amino acids. Cells were maintained in a $5 \% \mathrm{CO}_{2}$ humidified atmosphere. Human tTG $\mathrm{CDNA}^{21}$ cloned in the eukaryotic expression vector pSG5 (Stratagene, La Jolla, California, USA), was used to transfect MDCK cells by calcium phosphate precipitation. A stable cell clone, MDCK-tTG, expressing recombinant tTG was obtained by cotransfecting MDCK cells with pSV2-Neo (Clontech, Palo Alfo, California, USA) in a 10:1 ratio. Cotransfected cells were cultured in a selective medium

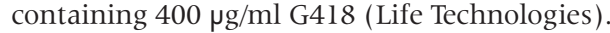

MDCK-tTG cells were harvested in $10 \mathrm{mM}$ Tris/ $\mathrm{HCl} \mathrm{pH} \mathrm{7.5,}$ $1 \mathrm{mM}$ ethylenediamine-tetraacetic acid (EDTA), and sonicated for 10 seconds. Protein content was estimated by the method of Bradford with bovine serum albumin (BSA) (Sigma, St Louis, Missouri, USA) as the standard.22

\section{$\lg G$ and $\lg A$ purification}

IgG and IgA antibodies from normal and CD patients were purified using Sepharose beads conjugated with protein A or rabbit antibodies to human IgA (Sigma). Serum was buffered with $0.1 \mathrm{M}$ Tris/HCl pH 8.0 and applied to the anti-human IgA Sepharose equilibrated in the same buffer. The flow through fraction, containing IgG, was collected and subsequently applied to protein A Sepharose. Bound antibodies were eluted with $0.1 \mathrm{M}$ glycine buffer $\mathrm{pH}$ 3.0; fractions were collected into tubes containing $1 \mathrm{M}$ Tris/ $\mathrm{HCl} \mathrm{pH} 8.0$ to prevent antibody denaturation. Protein content was determined using the method of Bradford. ${ }^{22}$

\section{Monoclonal antibodies}

Monoclonal antibodies (single chain antibody fragments) to tTG were prepared as described previously. ${ }^{20}$ Briefly, total RNA was prepared from intestinal biopsies from three previously untreated CD adult patients, cDNA was synthesised using random hexamers, and Ig $V$ regions were amplified using specific $\mathrm{V}$ region primers and assembled before cloning into the phagemid vector pDAN5. ${ }^{23}$ Antibodies to tTG were isolated by recursive cycles of binding to recombinant human tTG, washing, and elution of phage particles expressing antibody fragments on their surface. In the present work, clones 2.18, 3.7, and 4.2 were isolated from CD libraries whereas clone D5 1 was selected from a naïve library $y^{23}$ made from peripheral lymphocytes from healthy donors. The CD antibodies are reported according to the donor patient, and given reference numbers 2,3 , and 4 followed by the individual clone reference number.

Soluble antibodies were obtained by expression in HB2151 (K12, ara $\Delta$ (lac-pro), thi $/ F^{\prime}$ pro $A^{+} B^{+}$, lacI $\left.I^{a} Z \Delta M 15\right)$, a nonsuppressor Escherichia coli strain. Phages from individual colonies were infected into $\mathrm{HB} 2151$, grown to $\mathrm{OD}_{600} 0.2$, induced with $1 \mathrm{mM}$ isopropyl- $\beta$-D-thiogalactopyranoside, and further grown overnight at $28^{\circ} \mathrm{C}$. Antibodies were purified from supernatants of induced bacterial cultures by Ni-NTA chromatography (Qiagen, Germany) and dialysed against phosphate buffered saline (PBS) to obtain a concentration of approximately $0.2 \mathrm{mg} / \mathrm{ml}$.

\section{Enzyme linked immunosorbent assay (ELISA) for anti-tTG antibodies}

To measure serum IgA and IgG anti-tTG titres, we used an ELISA method. U bottomed microtitre plates (Falcon, Franklin Lakes, New Jersey, USA) were coated with 1 g g of human recombinant tTG per well in $100 \mu \mathrm{l}$ of coating buffer ( $50 \mathrm{mM}$ Tris/ $\mathrm{HCl}, 150 \mathrm{mM} \mathrm{NaCl}, 5 \mathrm{mM} \mathrm{CaCl}$, $\mathrm{pH}$ 7.5) for two hours at $37^{\circ} \mathrm{C}$. Wells were washed three times with washing buffer (50 mM Tris/HCl, $150 \mathrm{mM} \mathrm{NaCl}, 10 \mathrm{mM}$ EDTA, 0.1\% Tween-20, pH 7.4). The plates were incubated in washing buffer overnight at $4^{\circ} \mathrm{C}$. Sera, diluted 1:100 in the same buffer, were added to the wells and incubated for one hour at room temperature (RT). After three washes, the wells were incubated with $100 \mu \mathrm{l}$ of peroxidase conjugated rabbit antihuman IgA or peroxidase conjugated rabbit antihuman IgG (Dako, Denmark) diluted respectively 1:1000 and 1:3000 in the same buffer for one hour at RT. Unbound antibodies were removed with three washes and colour was developed by addition of $100 \mu \mathrm{l}$ of $1 \mathrm{M}$ sodium citrate, $1 \mathrm{M}$ citric acid, 1 $\mathrm{mg} / \mathrm{ml}$ o-phenylenediamine-hydrochloride (Sigma), and $0.06 \% \mathrm{H}_{2} \mathrm{O}_{2}$ (Carlo Erba, Italy), pH 5, at RT for 30 minutes in the dark. Absorbances were read on an ELISA reader (SpectraCount, Packard, Milan, Italy) at $450 \mathrm{~nm}$. All samples were tested in duplicate. Values were expressed as percentage of a reference pool of sera obtained from untreated coeliac patients.

\section{In vitro tTG assay}

Enzyme activity was assayed by a radiometric method based on $\mathrm{Ca}^{2+}$ dependent incorporation of $\left[{ }^{3} \mathrm{H}\right]$ spermidine (Nen Life Science Products, Boston, Massachusetts, USA) into $N, N$ dimethylated casein (DMC). Briefly, the assay mixtures (100 pl) containing $125 \mathrm{mM}$ Tris/HCl buffer, $\mathrm{pH}$ 8.0, $10 \mathrm{mM}$ dithiotreitol, $5 \mathrm{mM} \mathrm{CaCl}{ }_{2}, 0.16 \mu \mathrm{M}\left[{ }^{3} \mathrm{H}\right]$ spermidine (15 $\mathrm{Ci} / \mathrm{mmol}$ ), $0.2 \mathrm{mg}$ DMC and, as enzymatic source MDCK-tTG cell homogenate $\left(7 \mu \mathrm{g}\right.$ of proteins), were incubated at $37^{\circ} \mathrm{C}$ for one hour. The inhibition studies were performed by preincubation of the enzyme with different amounts of IgG and IgA in $25 \mathrm{mM}$ Tris/ $\mathrm{HCl} \mathrm{pH} 8.0$ (final volume $20 \mu \mathrm{l}$ ) at $20^{\circ} \mathrm{C}$ for 10 minutes. Preincubation of tTG with different amounts of monoclonal antibodies was performed in the absence or presence of $5 \mathrm{mM} \mathrm{CaCl}_{2}$. Blanks were simultaneously run with $5 \mathrm{mM}$ ethylene glycol-bis( $\beta$-aminoethyl ether) $N, N, N^{\prime}, N^{\prime}$ tetraacetic acid (EGTA). The reactions were stopped with $10 \%$ trichloroacetic acid containing $2 \mathrm{mM}$ unlabelled spermidine. After centrifugation, the precipitates were washed twice with the same solution, dissolved in $0.5 \mathrm{ml}$ of $0.2 \mathrm{~N} \mathrm{NaOH}$, and finally counted in $5 \mathrm{ml}$ of Pico-Fluor 40 scintillation mixture (Packard).

\section{In situ tTG activity assay}

Umbilical cord cryostat sections (7 $\mu$ m thick) were mounted on slides with $2 \%$ triethoxysilyl-propylamin (Merck, Germany) in acetone, air dried for 60 minutes at RT, and fixed in acetone for 10 minutes. Sections were preincubated with $1 \%$ BSA in $100 \mathrm{mM}$ Tris/HCl, pH 7.4, for 30 minutes at RT, and then for two hours at RT with biotinylated monodansylcadaverine (bio-MDC) (Molecular Probes, Leiden, the Netherlands). This substrate solution was prepared by adding $10 \mu \mathrm{l}$ of $10 \mathrm{mM}$ bio-MDC and $25 \mu \mathrm{l}$ of $200 \mathrm{mM} \mathrm{CaCl}_{2}$ solution to $965 \mu \mathrm{l}$ of $100 \mathrm{mM}$ Tris/ $\mathrm{HCl}, \mathrm{pH}$ 7.4. The tTG reaction was stopped with $25 \mathrm{mM}$ EDTA for five minutes. Incorporation of labelled substrate was visualised by incubation in a humid chamber for 30 minutes at RT with streptavidin fluorescein isothiocyanate conjugate (Dako) diluted 1:50 in PBS. Finally, sections were washed twice in PBS and mounted in 10\% glycerol in PBS. In control sections, $200 \mathrm{mM} \mathrm{CaCl}$, was replaced by $200 \mathrm{mM}$ EDTA. Photographs were taken using an Axiophot (Zeiss, Germany) and colour reversal film (Kodak, UK).

\section{RESULTS}

Effects of CD patient IgG and IgA on tTG activity in vitro Table 1 shows that addition of $10 \mu \mathrm{g}$ of IgG and IgA from six and five $\mathrm{CD}$ patients, respectively, into the assay mixture inhibited the incorporation of $\left[{ }^{3} \mathrm{H}\right]$ spermidine into DMC catalysed by recombinant tTG expressed in the MDCK-tTG cell line. A different rate of inhibition among patients was also observed. In fact, the extent of inhibition due to IgG and IgA 
Table 1 Effects of $\lg G$ and $\lg A$ purified from the serum of patients with coeliac disease and controls on tissue transglutaminase ( $\mathrm{tTG}$ ) activity

\begin{tabular}{llcc}
\hline Antibody & Patients & \% inhibition* & Titres $\dagger$ \\
\hline $\lg G$ & Control & $0 \quad(0.5)$ & 2 \\
$\lg G$ & 1 & $13.3(3.7)$ & 39 \\
$\lg G$ & 2 & $16.0(2.5)$ & 37 \\
$\lg G$ & 3 & $8.3(4.3)$ & 89 \\
$\lg G$ & 4 & $24.0(1.0)$ & 37 \\
$\lg G$ & 5 & $14.0(3.1)$ & 54 \\
$\lg G$ & 6 & $11.7(2.0)$ & 90 \\
& & & \\
$\lg A$ & Control & $0(0.5)$ & 2 \\
$\lg A$ & 2 & $39.0(1.0)$ & 92 \\
$\lg A$ & 3 & $22.0(2.0)$ & 46 \\
$\lg A$ & 4 & $14.5(1.5)$ & 53 \\
$\lg A$ & 5 & $19.5(5.0)$ & 30 \\
$\lg A$ & 6 & $11.1(1.5)$ & 29 \\
\hline
\end{tabular}

*Values represent the mean of two replicates in two independent sets of experiments; $10 \mu \mathrm{g}$ of purified $\lg G$ or $\lg A$ was used in each in vitro assay tube.

†Titres were measured by ELISA and expressed as percentage of a reference pool of sera

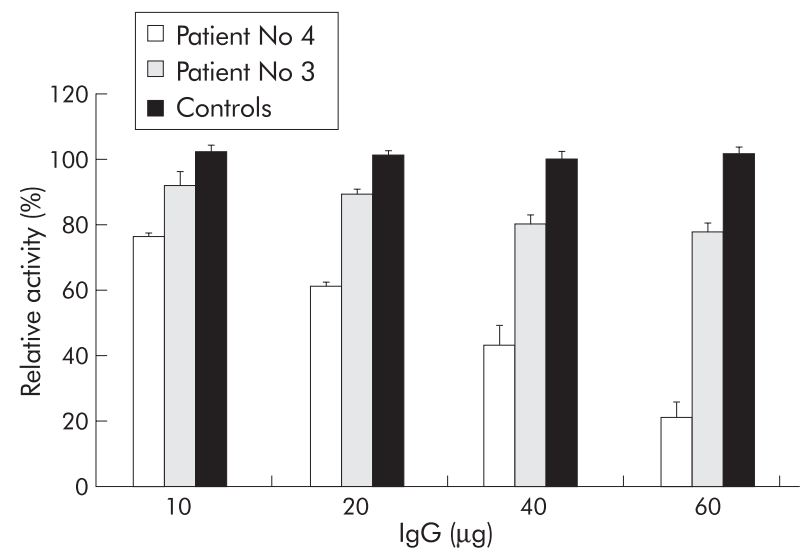

Figure 1 Effect of purified serum IgG from coeliac patients (Nos 3 and 4 ) and from healthy controls on tissue transglutaminase (tTG) activity. Increasing amounts of lgG from patient No 4 (titre 24\%), lgG from patient No 3 (titre $89 \%$ ), and lgG from a pool of control patients (titre $2 \%$ ) were incubated with $7 \mathrm{\mu g}$ of proteins from Madin-Darby canine kidney (MDCK)-tTG cells at $37^{\circ} \mathrm{C}$ for one hour in a $100 \mu l$ final volume. The activity of $\mathrm{TTG}$ was calculated as a percentage of basal activity (no lgG addition) within MDCK-tTG cells. Data are presented as means (SD) from three separate experiments done in duplicate.

ranged from $8.3(4.3) \%$ to $24(1) \%$ and from $11.1(1.5) \%$ to 39 (1)\%, respectively. The data reported in table 1 also showed that there was no correlation between the degree of inhibition and serum IgG or IgA titres measured by ELISA. This behaviour was confirmed when a dose dependent inhibition assay was performed using IgG and IgA from two different patients (Nos 3 and 4 in table 1). In fact, as shown in fig 1, the inhibition exhibited by IgG from patient No 4 (titre 37\%) was dose dependent and reached $80 \%$ when $60 \mu \mathrm{g}$ of antibody were used with respect to basal values obtained by preincubating the enzyme in the absence of antibody. In contrast, IgG from patient No 3 (titre $89 \%$ ) exerted 20\% inhibition at the higher concentration used. Finally, IgG purified from healthy controls had no effect on tTG activity.

\section{Effects of monoclonal anti-tTG antibodies on tTG activity in vitro}

The monoclonal antibody CUB 7402 displayed a dose dependent inhibitory effect towards the catalytic activity of the

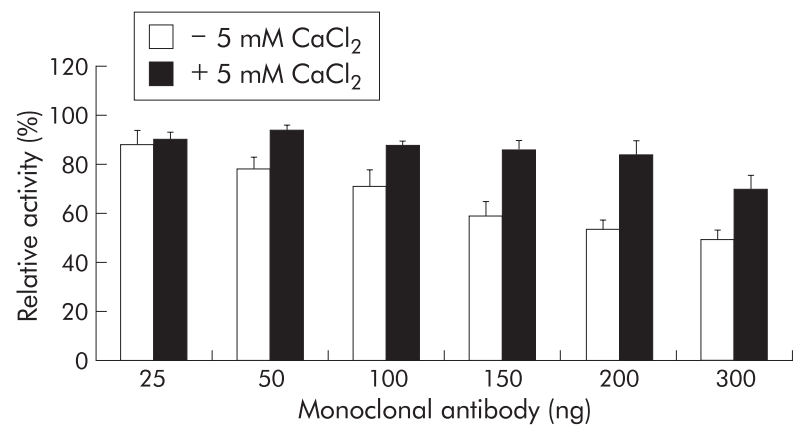

Figure 2 Effect of the monoclonal antibody anti-tissue transglutaminase (TTG) (CUB 7402) on TTG activity in response to $\mathrm{Ca}^{2+}$. Increasing concentrations of CUB 7402 were preincubated at $20^{\circ} \mathrm{C}$ for 10 minutes in $20 \mu$ of $25 \mathrm{mM}$ Tris $/ \mathrm{HCl}, \mathrm{pH} 8.0$, in the absence or presence of $5 \mathrm{mM} \mathrm{CaCl}$, with $7 \mathrm{\mu g}$ of proteins from Madin-Darby canine kidney (MDCK)-fTG cells. The samples were further incubated for one hour at $37^{\circ} \mathrm{C}$ in a $100 \mu$ final volume. The activity of TTG was calculated as a percentage of basal activity (no CUB 7402 added) within MDCK-TTG cells. Data are presented as means (SD) from three separate experiments performed in duplicate.

enzyme expressed in MDCK-tTG cells with respect to basal values, as shown in fig 2 . Because calcium ions influence tTG activity by inducing structural changes in the protein, we preincubated the enzyme, before the enzymatic assay, with different amounts of antibodies in $25 \mathrm{mM}$ Tris/ $\mathrm{HCl} \mathrm{pH} 8.0$ in the presence of $5 \mathrm{mM} \mathrm{CaCl}_{2}$. Preincubation caused loss of the inhibitory effect due to CUB 7402 .

The same experiments were performed using monoclonal antibodies to tTG derived from both intestinal lymphocytes from three patients with $\mathrm{CD}$ and from peripheral blood lymphocytes from healthy subjects. The results reported in fig 3 show that the dose related inhibition caused by $4.2,2.18$, and 3.7 clones was almost the same (ranging from 20\% to $40 \%$ ). However, when preincubation was performed in the presence of $\mathrm{CaCl}_{2}$, inhibition was still present; in particular, when 2.18 clone was used, enhanced inhibition was observed.

Finally, only a weak inhibitory effect was evoked by the anti-tTG monoclonal antibody derived from peripheral blood lymphocytes from healthy subjects, suggesting that the anti-tTG antibodies found in CD have special properties which may play a role in the disease.

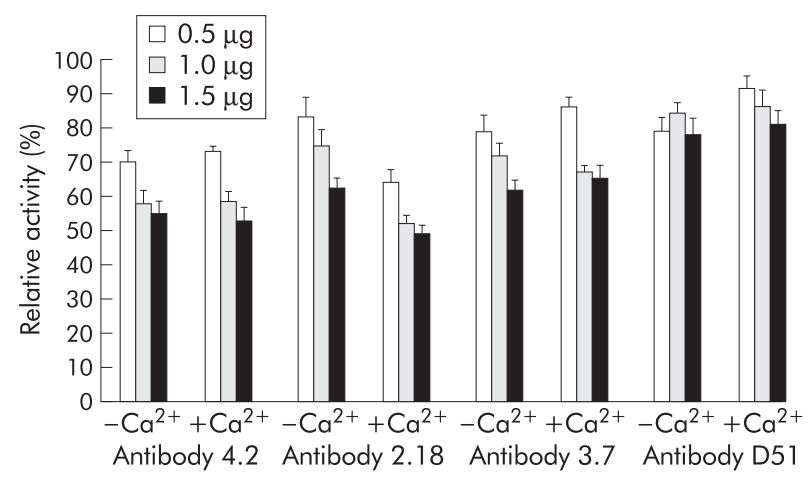

Figure 3 Effect of single chain monoclonal antibodies on tissue transglutaminase (tTG) activity in response to $\mathrm{Ca}^{2+}$. Human monoclonal antibodies $(0.5,1.0$, and $1.5 \mu \mathrm{g})$ were preincubated at $20^{\circ} \mathrm{C}$ for 10 minutes in $20 \mu$ of $25 \mathrm{mM}$ Tris $/ \mathrm{HCl}, \mathrm{pH} 8.0$, in the absence (-) or presence (+) of $5 \mathrm{mM} \mathrm{CaCl}$, with $7 \mu \mathrm{gg}$ of proteins from Madin-Darby canine kidney (MDCK)-tTG cells. The samples were further incubated for one hour at $37^{\circ} \mathrm{C}$ in a $100 \mu$ final volume. The activity of tTG was calculated as a percentage of basal activity (no antibodies added) within MDCK-tTG cells. Data are presented as means (SD) from three separate experiments performed in duplicate. 

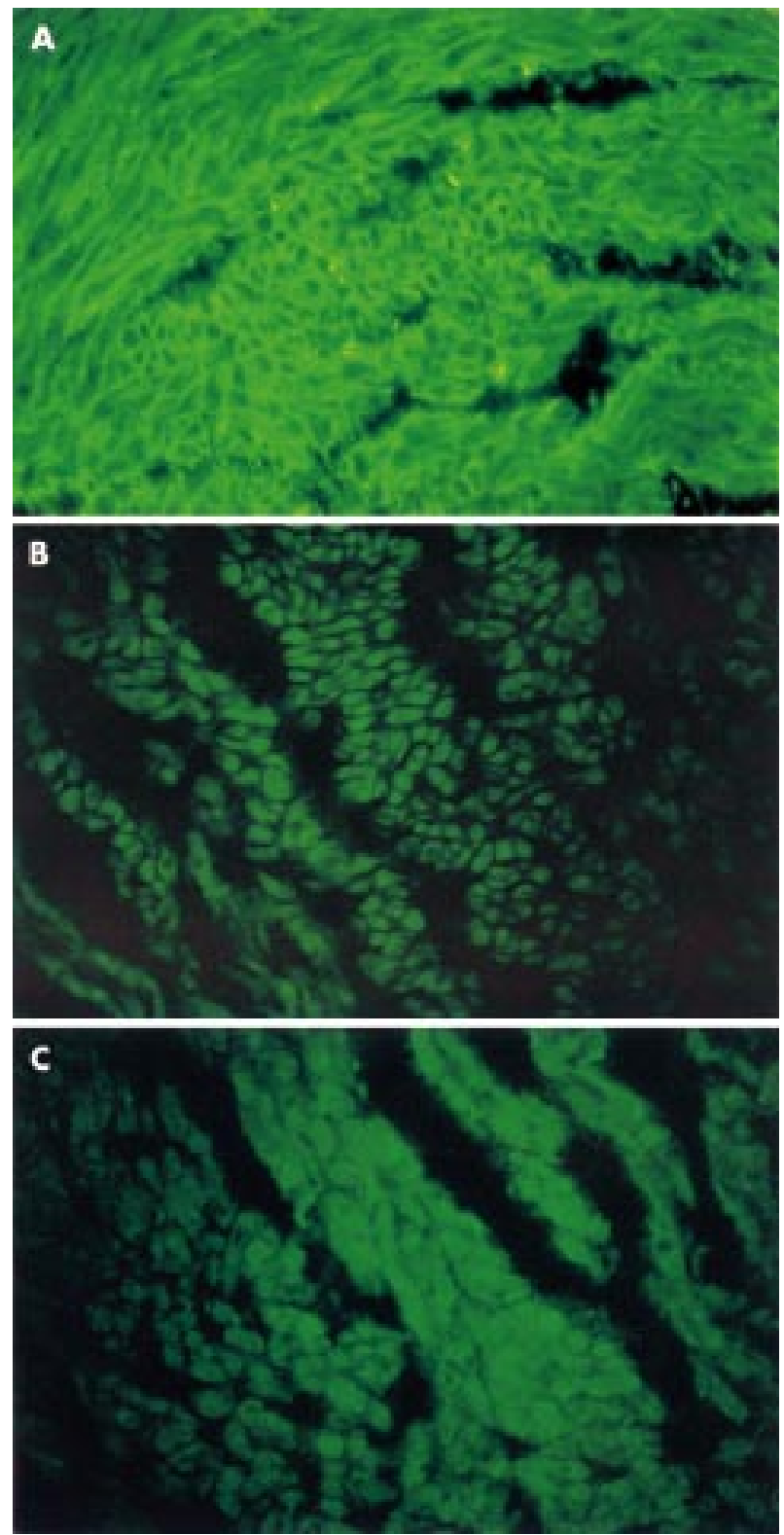

Figure 4 Effect of specific antibodies on tissue transglutaminase (tTG) activity in human umbilical cord. The signal corresponds to incorporation of substrate biotinylated monodansyl-cadaverine (A). Sections treated with the anti-TT CUB 7402, diluted 1:25 (B), and with monoclonal antibody 4.2 , undiluted (C), showed a significantly lower signal (original magnification $\times 400$ ).

\section{Effect of antibodies on ITG activity in situ}

tTG activity, as detected in umbilical cord sections by incorporation of the labelled substrate bio-MDC, resulted in the presence of fluorescent signals (fig 4A). Such activity was clearly affected by addition of antibodies. Anti-tTG CUB 7402 (fig 4B) and single chain monoclonal antibodies from the intestinal mucosa of coeliac patients (fig 4C) significantly decreased signalling. Both IgG and IgA from coeliac serum, but not from controls, significantly decreased the signalling (data not shown)

\section{DISCUSSION}

The recent identification of tTG as the main endomysial autoantigen recognised by $\operatorname{IgA}$ from patients with $\mathrm{CD}^{17}$ allowed the implementation of ELISA based tests, initially based on guinea pig tTG and subsequently on human tTG, in the clinical diagnosis of $\mathrm{CD}^{18}{ }^{19}{ }^{24}$ Interestingly, IgA from coeliac sera preferentially bind $\mathrm{Ca}^{2+}$ activated $\mathrm{tTG},{ }^{24}{ }^{25}$ suggesting the recognition of conformational epitopes in the enzyme. The mechanism of formation of these antibodies is not presently understood. It has been proposed that gliadin specific $\mathrm{T}$ cells provide cognate help for their production by tTG specific B cells ${ }^{26}$ to explain the strict gluten dependence. Similarly, the possible role of these autoantibodies in the pathogenesis of mucosal damage is uncertain. ${ }^{27}$ Although most evidence suggests a gliadin triggered Thl mechanism of damage, ${ }^{14}$ it is very important to address the question of their possible contribution to the intestinal lesion, given the strong disease specific presence of tTG antibodies and the role played by this enzyme in several crucial biological processes. So far only indirect evidence has been provided: it has recently been shown that transforming growth factor $\beta$ (TGF- $\beta$ ) dependent differentiation of T84 crypt epithelial cells in a fibroblast coculture model can be prevented by the addition of anti-tTG IgA. ${ }^{28}$ These authors suggested that blocking tTG prevented the generation of the active form of TGF- $\beta$ which relies on tTG for its maturation, and they further speculated that anti-tTG antibodies may also affect the differentiation of the coeliac epithelium. In this paper, we have directly addressed the issue of whether anti-tTG antibodies can modulate the activity of the enzyme in any way.

Our results demonstrate for the first time that IgA and IgG from serum of CD patients as well as monoclonal anti-tTG antibodies, especially those obtained from CD patients, display inhibitory effects towards the catalytic activity of human tTG both in vitro and in situ. Inhibition of recombinant human tTG activity was shown in all sera tested although the degree of inhibition was different from case to case. Moreover, the extent of such inhibition did not correlate with the titre of antibodies measured by ELISA. Take together, the data indicate that more than one epitope is recognised by sera from different patients. Also interesting were the data obtained with monoclonal antibodies produced by B cells present in the coeliac lesion. Antibodies obtained from a phage antibody library produced both from peripheral blood and from CD patients recognised different tTG epitopes. These antibodies were isolated from three CD patients and shown to recognise two main conformational tTG epitopes. ${ }^{20}$ In the present study, four monoclonal antibodies were chosen for the inhibition experiments: clones 2.18 and 4.2 belonging to the two categories as above, 3.7 with uncertain attribution, and D5 I derived from healthy donor peripheral lymphocytes. Interestingly, all of the monoclonal antibodies from CD patients showed inhibitory activity whereas D51, obtained from non-coeliac subjects, did not show any inhibitory activity, implying that tTG antibodies from healthy subjects may not bind to epitopes related to substrate combining sites of tTG.

tTG is subject to fine regulation, involving calcium and GTP which, respectively, activate and inhibit transamidating activity by inducing conformational changes. ${ }^{629}$ Recently, using experimental approaches and computer modelling, a three dimensional model was proposed in which the protein core domain, containing the catalytic site, becomes accessible to macromolecular substrates as a consequence of calcium binding. ${ }^{30}$ The catalytic domain extends from amino acid 140 to 454 , also containing the three putative calcium binding regions comprising residues 146-162, 229-234, and 434$452,{ }^{31}$ while the GTP binding site was located in the region $1-180 .{ }^{32}$ We have tested the consequences of the presence of calcium ions during preincubation of recombinant human tTG with monoclonal antibodies from patients. Calcium did not interfere with the inhibitory activity implying that the change in conformation induced by calcium ions did not affect the antibody binding site: indeed, in one case stronger inhibition was observed. In contrast, preincubation with calcium ions before assay blocked the inhibition induced by CUB 7402. It is known that CUB 7402 maps the linear epitope $447-478$ of tTG which overlaps the calcium binding region 343-452: calcium 
could thus mask the binding site of the antibody interfering with its inhibitory activity.

Although inhibition was shown in in vitro experiments, the potential importance of this finding in the in vivo situation is suggested by in situ inhibition of tTG activity in umbilical cord tissue. Even so, it is difficult to predict the relevance in the pathogenesis of the coeliac lesion. Firstly, the inhibition we have observed is far from complete and the residual enzymatic activity could well be sufficient to fulfil all tTG biological functions; and secondly, it has recently been reported that tTG knockout mice have a normal small intestinal architecture, ${ }^{33}$ suggesting that the biological function of tTG may be replaced by other enzymes, although it cannot be excluded that anti-tTG antibodies may also inhibit these putative enzymes.

In conclusion, we have shown that CD related anti-tTG autoantibodies can inhibit enzyme activity. Further research is required to clarify to what extent this could play a role in the modulation of $\mathrm{T}$ cell activity and/or, independent of $\mathrm{T}$ cells, contribute to the mucosal lesion in CD.

\section{ACKNOWLEDGEMENTS}

This study was carried out with the financial support of Telethon-Italy (grant No E.1141); the commission of the European Communities, specific RTD programme "Quality of Life and Management of Living Resources", QLK1-CT-1999-00037, Evaluation of the prevalence of coeliac disease and its genetic components in the European population. The work was partly supported also by MURST (PRIN), and by Regione Campania (Ricerca Sanitaria Finalizzata).

\section{Authors' affiliations}

C Esposito, Department of Chemistry, University of Salerno, Italy F Paparo, M Maglio, S Auricchio, R Troncone, Department of Paediatrics and European Laboratory for the Investigation of Food-Induced, Diseases, University Federico II, Naples, Italy

I Caputo, R Porta, Department of Food Science, University Federico II, Naples, Italy

M Rossi, Institute for Food Science, CNR, Avellino, Italy

D Sblattero, R Marzari, Department of Biology, University of Trieste,

Trieste, Italy

T Not, IRCCS Burlo Garofalo, Trieste, Italy

\section{REFERENCES}

1 Folk JE, Finlayson JS. The $\epsilon-(\gamma$-glutamyl)|lysine cross-link and the catalytic role of transglutaminases. Adv Protein Chem 1977;31:1-133.

2 Lorand L, Conrad SM. Transglutaminases. Mol Cell Biochem 1984;58:9-35

3 Aeschlimann D, Paulsson M. Transglutaminases: protein cross-linking enzymes in tissues and body fluids. Thromb Haemost 1994:71:402-15.

4 Lu S, Saydak M, Gentile V, et al. Isolation and characterization of the human tissue transglutaminase gene promoter. J Biol Chem 1995;270:9748-56

5 Kuncio GS, Tsyganskaya M, Zhu J, et al. TNF- $\alpha$ modulates expression of the tissue transglutaminase gene in liver cells. Am J Physiol 1998;274:G240-45

6 Feng J-F, Readon M, Yadav SP, et al. Calreticulin down-regulates both GTP binding and transglutaminase activities of transglutaminase II. Biochemistry 1999;38:10743-9.

7 Melino G, Piacentini M. "Tissue" transglutaminase in cell death: a downstream or a multifunctional upstream effector? Febs Lett 1998;430:59-63.
8 Aeschlimann D, Thomazy V. Protein crosslinking in assembly and remodelling of extracellular matrices: the role of transglutaminases. Connect Tissue Res 2000;41:1-27.

9 Nakaoka H, Perez DM, Baek KJ, et al. $G_{h}$ : a GTP binding protein with transglutaminase activity and receptor signaling function. Science 1994;264:1593-6.

10 Zhang J, Tucholski J, Lesort $M$, et al. Novel bimodal effects of the G-protein tissue transglutaminase on adrenoreceptor signaling. Biochem J 1999:343:541-9.

11 Piacentini $\mathbf{M}$, Colizzi V. Tissue transglutaminase: apoptosis versus autoimmunity. Immunol Today 1999;20:130-4.

12 Utz PJ, Anderson P. Posttranslational protein modifications, apoptosis, and the bypass of tolerance to autoantigens. Arthritis Rheum 1998:41:1152-60.

13 Piredda L, Amendola A, Colizzi V, et al. Lack of tissue transglutaminase protein cross-linking leads to leakage of macromolecules from dying cells: relationship to development of autoimmunity in MRL/pr/lpr mice. Cell Death Differ 1997:4:463-72.

14 Sollid LM. Molecular basis of celiac disease. Annu Rev Immunol 2000; 18:53-81

15 Kagnoff MF. HLA genes in coeliac disease. In: Auricchio S, Greco L, Maiuri L, et al, eds. Coeliac disease. Naples: JGC Editions, 2000:5-14

16 Mäki M. The humoral immune system in coeliac disease. Baillieres Clin Gastroenterol 1995:9:231-49.

17 Dieterich W, Enhis T, Baver M, et al. Identification of tissue transglutaminase as the autoantigen of celiac disease. Nat Med 1997;3:797-801

18 Troncone R, Maurano F, Rossi M, et al. IgA antibodies to tissue transglutaminase: an effective diagnostic test for celiac disease. J Pediatr 1999:134:166-71.

19 Sblattero D, Berti I, Trevisiol C, et al. Human recombinant tissue transglutaminase ELISA: an innovative diagnostic assay for celiac disease. Am J Gastroenterol 2000;95: 1253-7.

20 Marzari R, Sblattero D, Florian F, et al. Molecular dissection of the tissue transglutaminase autoantibody response in celiac disease. J Immunol 2001;166:4170-6.

21 Gentile V, Saydak M, Chiocca EA, et al. Isolation and characterization of cDNA clones to mouse macrophage and human endothelial cell tissue transglutaminases. J Biol Chem 1991;266:478-83.

22 Bradford MM. A rapid and sensitive method for the quantitation of microgram quantities of protein utilizing the principle of protein-dye binding. Anal Biochem 1976:72:248-54.

23 Sblattero D, Bradbury A. Exploiting recombination in single bacteria to make large phage antibody libraries. Nat Biotechnol 2000;18:75-80.

24 Dieterich W, Laag E, Schöpper H, et al. Autoantibodies to tissue transglutaminase as predictors of celiac disease. Gastroenterology 1998;115:1317-21.

25 Sulkanen S, Halttunen T, Laurila $\mathrm{K}$, et al. Tissue transglutaminase autoantibody enzyme-linked immunosorbent assay in detecting celiac disease. Gastroenterology 1998;115:1322-8

26 Sollid LM, Molberg O, McAdam S, et al. Autoantibodies in celiac disease: tissue transglutaminase guilt by association? Gut 1997:41:851-2.

27 Molberg O, McAdam SN, Sollid LM. Role of tissue transglutaminase in celiac disease. J Pediatr Gastroenterol Nutr 2000;30:232-40.

28 Halttunen T, Mäki M. Serum immunoglobulin A from patients with celiac disease inhibits human T84 intestinal crypt epithelial cell differentiation. Gastroenterology 1999;116:566-72.

29 Monsonego A, Friedemann I, Shani Y, et al. GTP-dependent conformational changes associated with the functional switch between $\mathrm{G} \alpha$ and cross-linking activities in brain-derived tissue transglutaminase. J Mol Biol 1998;282:713-20.

30 Casadio R, Polverini E, Mariani P, et al. The structural basis for the regulation of the tissue tranglutaminase by calcium ions. Eur J Biochem 1999:262:672-9.

31 Nakanishi K, Nara K, Hagiwara $\mathrm{H}$, et al. Cloning and sequence analysis of cDNA clones for bovine aortic-endothelial-cell transglutaminase. Eur J Biochem 1991;202:15-21

32 Lai TS, Slaughter TF, Koropchak CM, et al. C-terminal deletion of human tissue transglutaminase enhances Mg-dependent GTP/ATP-ase activity. J Biol Chem 1996;271:31191-5.

33 De Laurenzi V, Melino G. Gene disruption of tissue transglutaminase. Mol Cell Biol 2001;21:148-55. 